\title{
Technology and Innovation Management Indicators and Assessment Based on Government Performance
}

\author{
UDC:005.591.6 \\ 005.332.330.341.1 \\ DOI: 10.7595/management.fon.2016.0001
}

\begin{abstract}
Throughout large global databases, such as OECD, UNDP, ITU, Eurostat, World Bank, and Statistical offices of countries, there are many indicators that refer to Technology and Innovation Management (TIM) performance of countries. However, a question arises of how to classify and systematically analyze these indicators in terms of measuring, monitoring and enhancing TIM performance at a national level. More specifically, in this paper we pose a question of how to assess the government performance in TIM, as one aspect of the Triple Helix model. Therefore, we use a model of thirty-nine indicators which are classified according to three main management functions: planning, organizing and control, observed as input, process and output, respectively. More importantly, we analyze the relations that exist between these three categories of indicators. Planning indicators are observed as the investments in technological and innovative activities; organizing indicators include the infrastructure, public administration efficiency and cooperation support, while control indicators refer to the national economy R\&D, transfer effects and entrepreneurship outcomes. The model is tested for assessing and comparing government performance in TIM for three countries: Serbia, Croatia and Slovenia, for the time period 2007-2012. Finally, as a feedback in the model, we used scores of the countries according to the Global Innovation Index and the Global Competitiveness Index, to verify the results and provide the final conclusion.
\end{abstract}

Keywords: Technology and Innovation Management, State/Government, Performance, Serbia

\section{Introduction}

The concept of the Triple Helix (TH) was proposed by Etzkowitz and Leydesdorff in the 1990s and today it is still developing through theoretical and empirical research. "The Triple Helix thesis is that the potential for innovation and economic development in a Knowledge Society lies in a more prominent role for the university and in the hybridization of elements from university, industry and government to generate new institutional and social formats for the production, transfer and application of knowledge" (Ranga \& Etzkowitz, 2013).

In recent decades, federal, state and local governments have created a variety of mechanisms to encourage knowledge-based economic development (Etzkowitz, 2002). The structure of a national R\&D system can be examined through the use of a Triple Helix framework that studies the relations among academia, business, and government (Etzkowitz, 2008). The development of a knowledge base is dependent on the condition that knowledge production should be socially organized. The interfaces between institutions and functions can be expected to resonate into co-evolutions in some configurations more than in others (Leydesdorff, 2006). This confirms the relevance of studying country specific university-industry-government configurations (see, for example, Rao, 2012; Park \& Leydesdorff, 2010).

Levi Jakšić et al. (2015) created a general model which measures Technology Innovation Management and Entrepreneurship effectiveness related to the key elements of the Triple Helix model. Based on the general model, in this paper we analyse one aspect of the Triple Helix model - the government sector, and introduce indicators for measuring and monitoring government performance in technology and innovation management (TIM). We classify the TIM performance indicators (of the government sector) into three basic management functions: planning, organizing and control (POC). Since we observe these management functions as input, 
process and output (respectively), and present indicators for their measurement, we are able to: (1) analyse if there exists a correlation between these three functions of TIM and (2) see which function is "ahead" of the others and which one "lags behind". This enables us to determine the weaknesses of the government sector performance in TIM. Finally, by comparing the results with the official competitiveness and innovativeness ranking of countries, we can assume the correlation that exists between the government performance in TIM and the country's innovativeness and competitiveness levels. We tested the model in cases of Serbia, Croatia and Slovenia for the period 2007-2012 and provided the appropriate cross-country comparisons.

\section{Triple Helix Concept and Government Performance}

The neo (institutional) perspective distinguishes three main configurations in the positioning of Triple Helix (TH) elements (Ranga \& Etzkowitz, 2013). In statists' configuration, government plays the leading role, driving academia and industry, but also limiting their capacity to initiate and develop innovative transformations. These examples could be found in Russia, China, some Latin American and Eastern European countries. Laissez-faire configuration is characterized by a limited government intervention in the economy (US, some Western Europe countries), with industry as the driving force and university with limited role in innovation, acting mainly as a provider. Government in the laissez-faire configuration is also limited, acting as a regulator of social and economic mechanisms. The Knowledge Society is characterized by balanced configuration where universities and other knowledge institutions act in partnership with industry and government and even take the lead in joint initiatives (Etzkowitz \& Leydesdorff, 2000). There has been a shift from the model of the state encompassing industry and academia. Development strategies, whether based primarily on the industrial sector as in the US or the governmental sector as in Latin America, are being supplemented, if not replaced, by knowledge-based economic development strategies, drawing upon resources from the three spheres of the Triple Helix (Etzkowitz, 2002).

Traditional performance measurement systems have concentrated on the development of indicators largely relating to economy (inputs) and efficiency (costs) due to the limited ability to measure effectiveness or outcomes in government organizations (Kloot and Martin, 2000). Although government is neither the supply nor, in most cases, the demand side of new knowledge and new technologies, it can promote effective enterpriseuniversity interaction in order to facilitate university technology transfer by institutional arrangements, policy making and so on (Rao et al, 2012).

According to Rao et al. (2012) there are two aspects of government R\&D investments: one is government R\&D funding which indirectly promotes university patent technology transfer activities by supporting teaching and research activities; the other is specialized government R\&D programs (foundation) which directly support university patent technology transfer activities. Thus, based on the triple helix theory, government R\&D investments, including government R\&D funding and government R\&D programs, can influence university patent technology transfer activities (Rao et al., 2012). It was shown (Chang-Yang, 2011) that it is difficult to evaluate the aggregate effect of public R\&D support. The author has found out that there are different effects of public R\&D support on firm R\&D, depending on various firm- or industry-specific characteristics. Four potential channels are identified: the technological-competence-enhancing effect, the demand-creating effect, the R\&D-cost-reducing effect and the (project) overlap (or duplication) effect.

The study (Caerteling et al., 2013) showed that government championship is an important positive factor for the performance of technology development projects. Government championing has more impact than government financial/technical assistance on both project performance and benefits to customers. There are cross-national differences in government R\&D funding in times of economic hardship (Kim, 2013). Strategic performance management demands an approach that is oriented towards financial measures, but also towards community concern and long-term development. Kloot and Martin (2000) presented the framework for performance-oriented approach in measuring local government performance, involving all stakeholders and non-financial measures.

Investments in science and technology (S\&T) are not the privilege of developed countries. According to Kim (2013) there is much to discover and learn from the experiences of non-OECD countries; in the recent years R\&D funding in the developing world, especially countries such as Brazil, Russia, India and China, have been soaring, defying the predictions based on their economic and social levels of development. Political leaders in these countries promote S\&T heavily as a springboard to move their nation forward in the increasingly knowledge-intensive economy of the 21 st century. 


\section{A Model for Measuring Government Performance in Technology and Innovation Management}

Many indicators and composite indices regarding TIM performance are observed and measured globally by well-known organizations such as OECD, World Bank, UNDP, UNData, UNESCO, WEF, Eurostat and ITU. In the effort to create models of the integrated performance measures based on indicators and composite indices, different institutions are involved and different methodologies are developed (Adams et al., 2006; Bandura, 2008; Levi Jakšić et al., 2015). Composite indicators are often used for benchmarking countries' performance, but they frequently stir controversies about the unavoidable subjectivity in their construction (Cherchye et al., 2008). The shortage we identified both in the literature and the published reports by the above mentioned organizations refer to the concrete analysis on government, university and industry performance in TIM. As highlighted by Singer and Peterka (2012), there are multiple indicators focused on measuring outputs at the level of industry, academia and government, but independent of each other and much less systematic approaches in monitoring influences of outputs of industry, university and government to outcomes (effectiveness). Based on Levi et al. (2015), Marinković et al. (2014) systematically analysed one aspect of the Triple Helix, the government sector performance in TIM, and presented indicators for its measurement and monitoring. The model, presented in Figure 1, consists of thirty-nine indicators of government performance in TIM, classified into three main categories: planning (nine indicators), organizing (eighteen indicators), and control (twelve indicators). We observe these three management functions also as three categories of indicators: input, process, and output, respectively. This is not the final list of government performance indicators in TIM, but it is the first attempt of the authors to create a systematic list of these indicators, which has to be re-examined, and potentially spread with more government performance indicators.

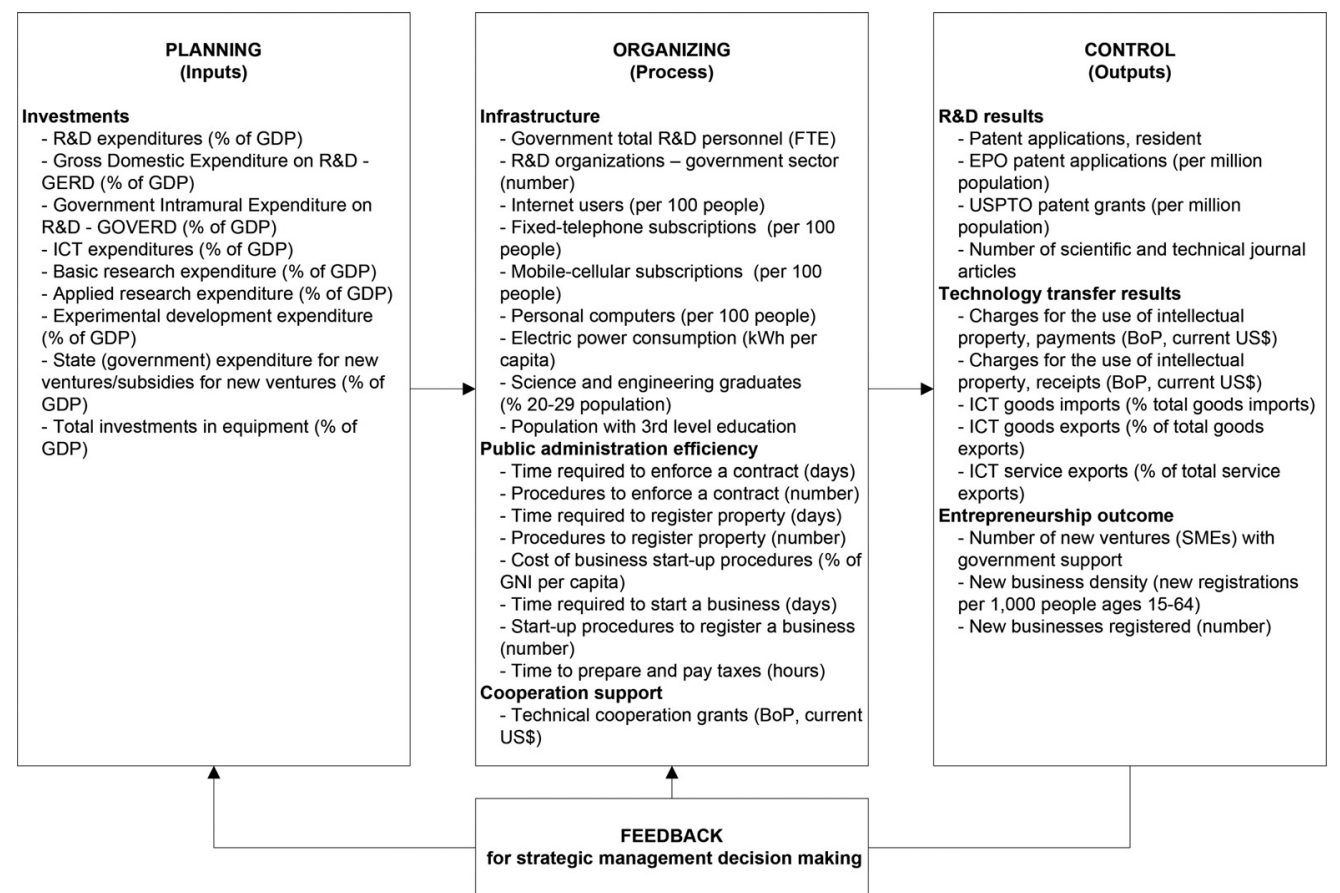

Figure 1: Model for measuring and monitoring government performance in TIM

(Marinković et al., 2014)

This model can be tested on any country. However, it is important to notice that when applying this model, it is possible to include only the indicators that are measured for the observed county. For example, OECD includes a limited number of countries, so GERD, GOVERD and HERD may not be included for assessing non-OECD countries performance, unless some author created reports of these indicators' values (such as the ERAWATCH reports, under the European Commission) for those countries. Marinković et al. (2014) applied and tested the model on the case of Serbia and included thirty-one out of thirty-nine identified government performance indicators in TIM, for the period 2008-2011, and calculated the indices of change over years which were the basis for comparing performance over time. 


\section{Application of the Model, Results and Discussion}

In this analysis we use the proposed model for assessing TIM performance of government sectors in Serbia, Croatia and Slovenia, and make the cross-country comparisons. For the selected countries, we have chosen fifteen indicators to observe: three for input (planning indicators), six for process (organizing indicators), and six for output (control indicators). We did not include all indicators from the model primarily because of the unavailability of all indicators values for all three countries, and secondly because it would be too extensive an analysis. We collected data from the following data bases: World Bank (2015), UNdata (2015), UNESCO (2015). As a feedback in the model we use GCl and Gll scores of countries, which represent their competitiveness and innovativeness levels. The period of analysis covers six years, from 2007 to 2012.

Considering the input indicators, we observe the following: R\&D expenditures, Gross Domestic Expenditure on R\&D - GERD, and R\&D performed by Government Sector. As we can firstly conclude from Figure 2, Slovenia is a leader among the observed countries regarding R\&D expenditures with almost $3 \%$ of GDP invested in R\&D in 2012. This is much higher than Serbia (almost $1 \%$ in 2012) and Croatia (0.75\% in 2012). However, it is good to notice the growing trend of R\&D expenditures in all three countries, meaning that they understand the necessity of investing for creating valuable output. The GERD results show the same picture (in 2012 Slovenia - $2.58 \%$, Serbia - $0.91 \%$ and Croatia - $0.75 \%$ ). However, it is not enough only to invest but also to create. So by these results, we could expect that Slovenia has a much better R\&D output in terms of patent activity than the other two courtiers. If we observe the structure of investments, namely the R\&D performed by the government sector, the situation is completely opposite - Slovenia with $12.29 \%$ in 2012 , Serbia with $28.76 \%$ (even $56.107 \%$ in 2008) and Croatia with $27.48 \%$. This result is unfortunately not encouraging for Serbia, since in developed countries R\&D expenditures come primarily from the business sector. This indicates that it could also be interesting to take a look at the distribution of research types among countries. It is well known that in Serbia the situation is not encouraging, since the majority of investments are directed towards fundamental research (50.2\% of the budget of the Ministry of Science and Technological development), and technological development projects (39.2\%), but a very small percent is invested in applied research (MSTD, 2010). Additionally, this results with poor patent activity of the country. The encouraging fact, however, is that a declining trend in R\&D performed by the government sector can be seen for both Slovenia and Serbia, indicating to a positively different structure of R\&D investments. In Croatia, the situation has not changed much over the observed period of time - from $25.49 \%$ in 2007 to $27.48 \%$ in 2012 .

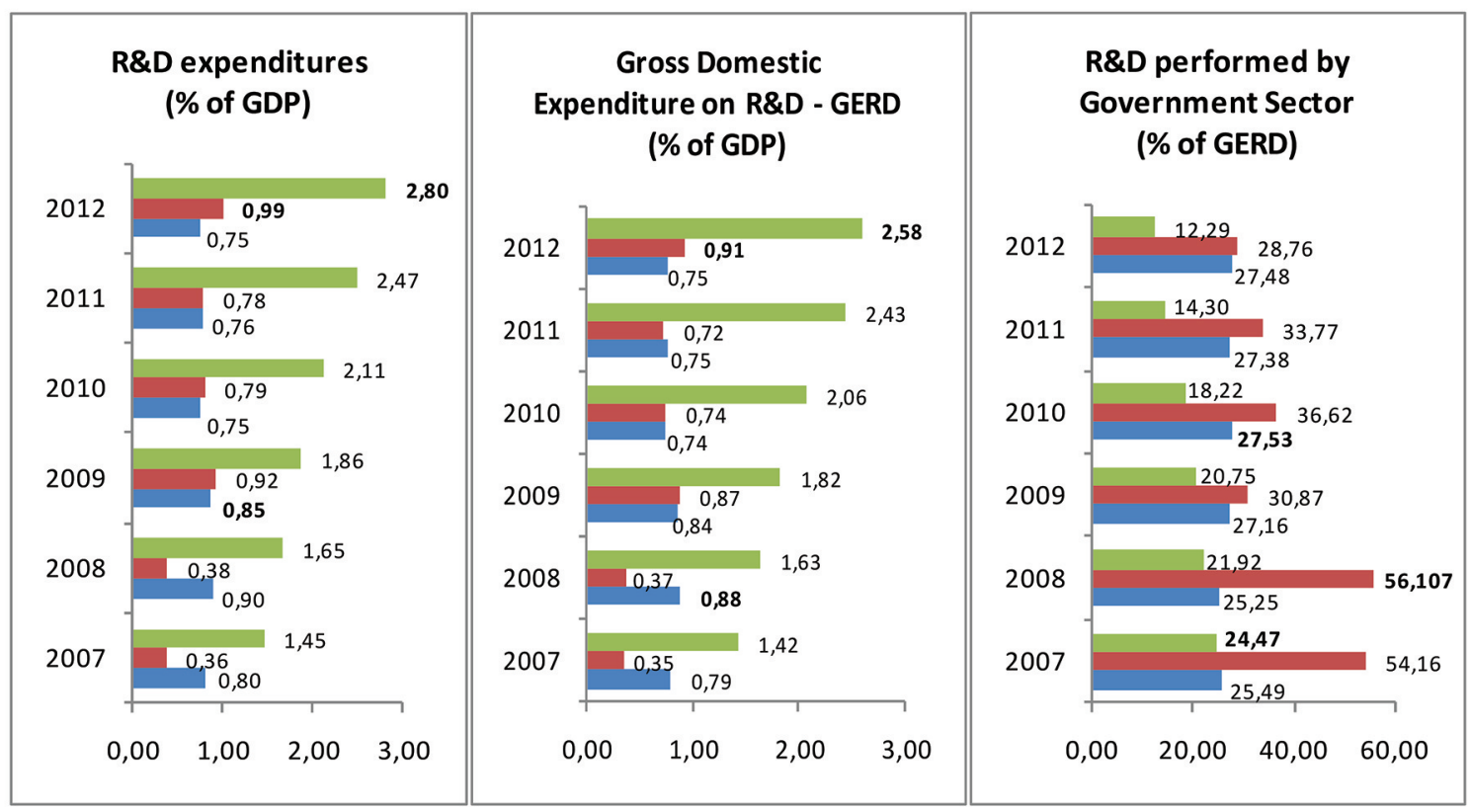

Slovenia nerbia ncroatia

Figure 2: Results of input indicators (investments), period 2007-2012 Source: World Bank (2015), UNdata (2015), UNESCO (2015) 
In order to come to the output side, we should first analyze the process (organizing) itself. The observed process indicators are presented in Figure 3. We observe infrastructure (first three indicators) and public administration efficiency (next 3 indicators).

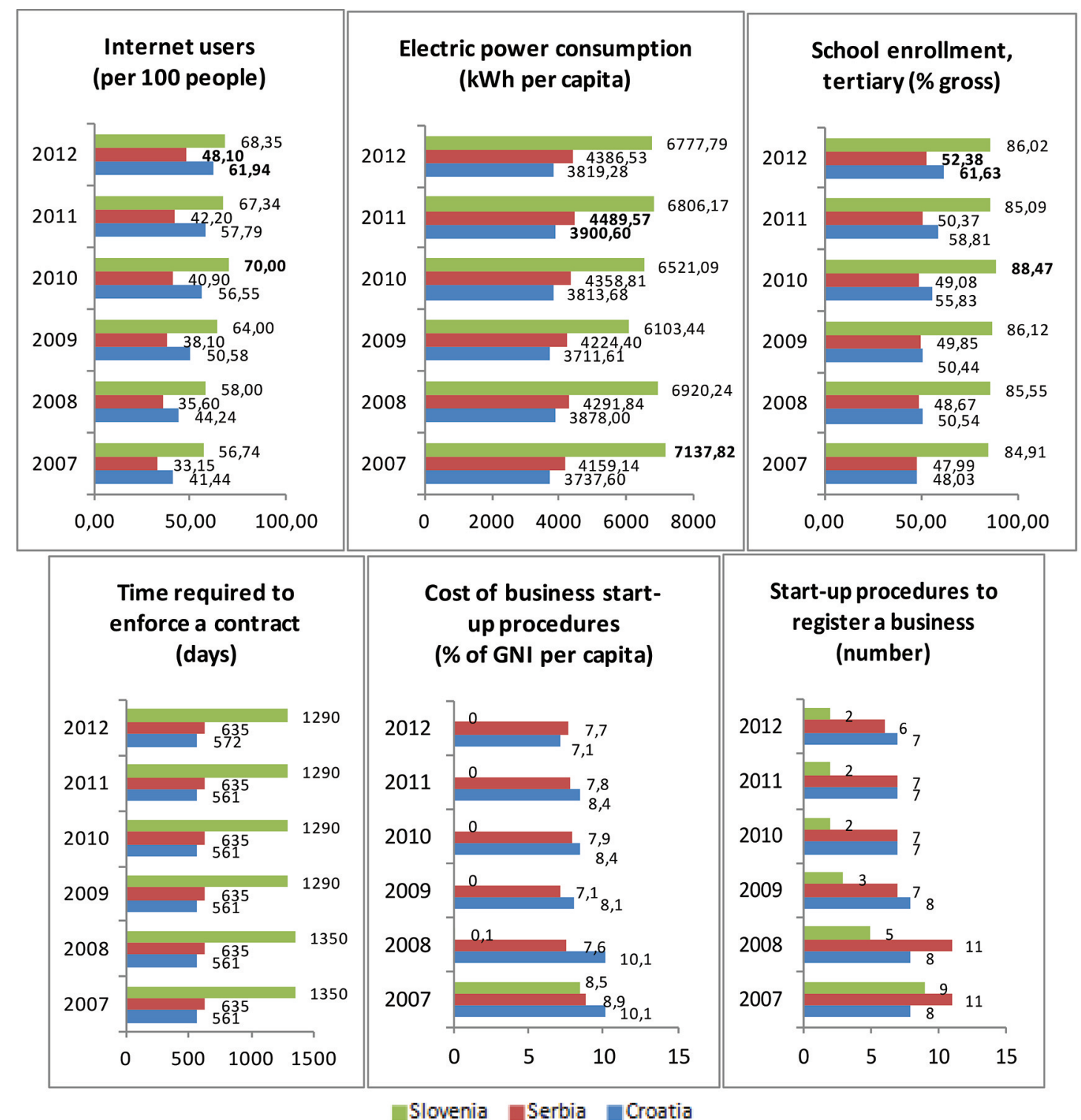

Figure 3: Results of process indicators (Infrastructure and Public administration efficiency), period 2007-2012; Source: World Bank (2015)

Regarding the infrastructure, the Internet users indicator shows an increasing trend in all three countries over the observed period of time. The situation is much better in Slovenia (more than $68 / 100$ people use the Internet) and Croatia (more than 60/100 people use the Internet) than in Serbia where around 48/100 people used the Internet in 2012. The situation with electric power consumption is slightly different. Slovenia is a leader, but Serbia is in the second place and Croatia in the third. It is interesting to notice that the electric power consumption has not changed much over the observed period of time for any of these countries. The third infrastructure indicator should be the Number of science and engineering graduates (\%20-29 population), but is not available for all three countries. So, we found an alternative one - tertiary school enrolment (\% gross). Slovenia leads with as high as $86.02 \%$, while in Serbia and Croatia it goes to 50 and $60 \%$, respectively. Looking at the second group of organizing indicators - public administration efficiency - we can 
see some discrepancies. It is very interesting that duration to enforce a contract is the longest for Slovenia (around 43 months), while at the same time they succeeded to reduce the costs of business of start-up procedures to $0 \%$ of GNI per capita (2009-2012) and have decreased the number of start-up procedures to register a business from 9 in 2007 to only 2 in 2012, providing a good stimulus for creating a start-up. The time required to enforce a contract is much shorter in both Serbia and Croatia (around 20 months in 2012), but the costs are much higher (around 7-8\% of GNI per capita for both countries). The number of procedures is also higher than in Slovenia - 6 for Serbia and 7 for Croatia in 2012. Considering these results, we can say that Slovenia has the best process values among the observed countries.

The output (control) indicators are presented in Figure 4. We observe patent activity (first two indicators), technology transfer results (next 3 indicators) and entrepreneurship outcome (1 indicator).

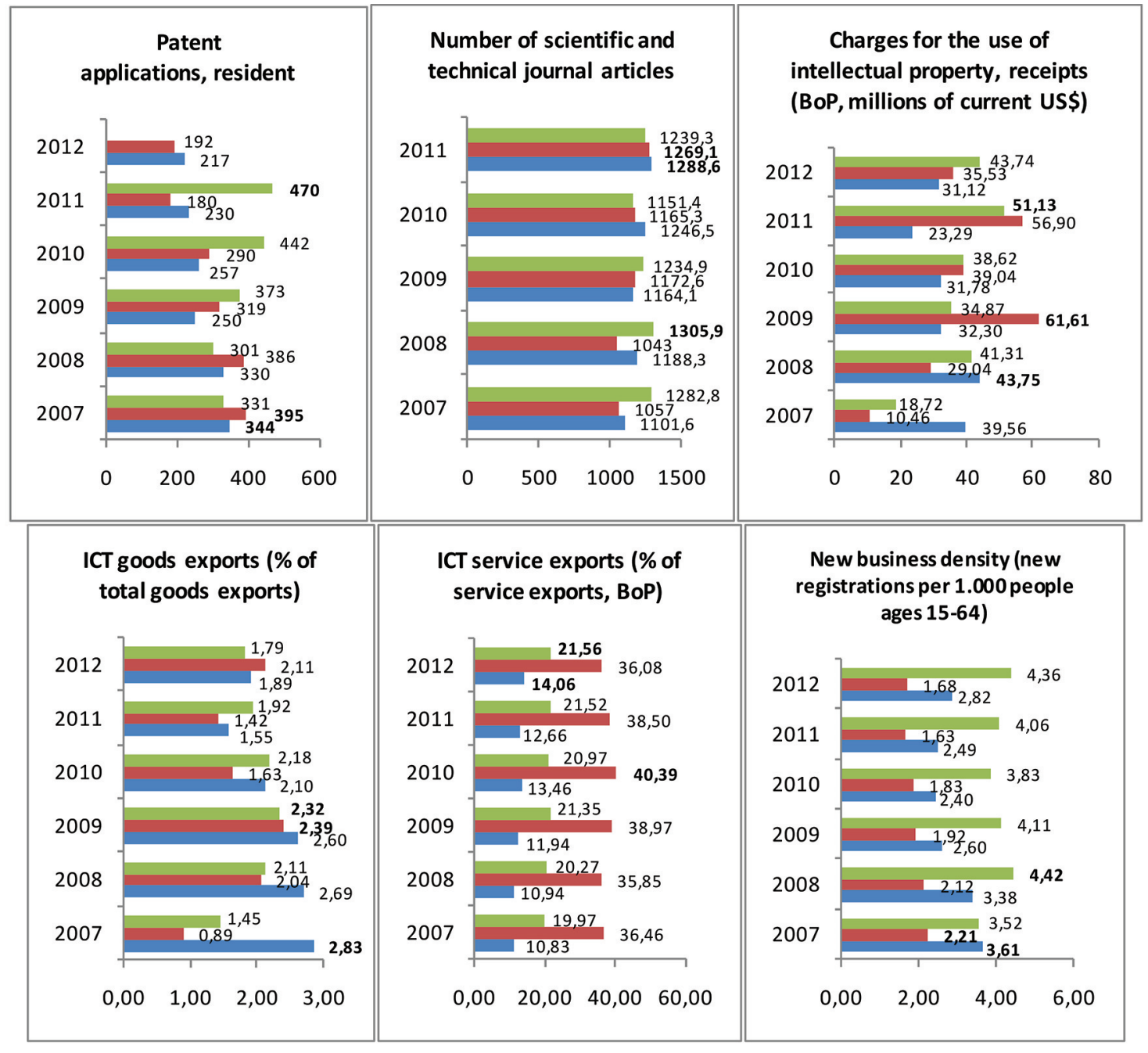

- Slovenia nSerbia nCroatia

Figure 4: Results of output indicators (R\&D results, TT results, and Entrepreneurship outcome), period 2007-2012; Source: World Bank (2015)

What was expected to be is that Slovenia leads when considering the number of resident patent applications (increased from 395 in 2007 to 470 in 2011). Data for 2012 are not available. On the other hand, although the investments increased over the observed period of time, in both Croatia and Serbia we can see a declining trend of patent applications (from 344 to 217 for Croatia, and from 395 to 192 for Serbia), which is quite a worrying fact that highlights the impotence of R\&D activities in these countries. This negative correlation between R\&D investments and patent activity of Serbia are elaborated in Levi Jakšić et al. (2014a). Regarding the 
number of scientific and technical journal articles, the situation is much more balanced among the observed countries, and has not changed much from 2007. The situation with charges for the use of IP is quite turbulent over the observed time period. Serbia was a leader in 2011, with more that 56 million US $\$$ receipts, while in 2012 this declined to around 35 million US\$. Unlikely, receipts in Slovenia increased from 18.72 in 2007 to 43.74 US\$ in 2012. Croatia has a turbulent situation and holds the third place from 2009, with around 31 million in 2012. Looking at the ICT export results, we can proudly conclude that Serbia has extremely good IT experts, since it is a leader in ICT service exports for the whole time period, resulting with around $40 \%$ of total service exports. At the same time, the share in Slovenia is much lower - around $20 \%$ and also in Croatia - around $10-14 \%$. Regarding ICT goods exports, Serbia also leads with more than $2 \%$ of total goods exports. Slovenia is the worst regarding this indicator. So, although having a fertile patent activity, Slovenia lacks results in technology transfer. Analyzing the entrepreneurship outcome, Slovenia has the best results in new business density for the whole time period. Croatia holds the second place, while Serbia lags behind. This is also an emerging topic since it is widely recognized that SMEs are an instrument for fighting poverty and underdevelopment (Mitanoski et al., 2013) and are drivers of economic growth and employment.

Finally, as a feedback, we give achieved scores of the countries, according to the World Economic Forum (WEF), and INSEAD - The Business School for the World and World Intellectual Property Office (WIPO) reports on $\mathrm{GCl}$ and $\mathrm{Gll}$, as measures of reached competitiveness and innovativeness levels. These results are given in Figure 5. We provide this additional analysis for a three-year period, 2010-2012.
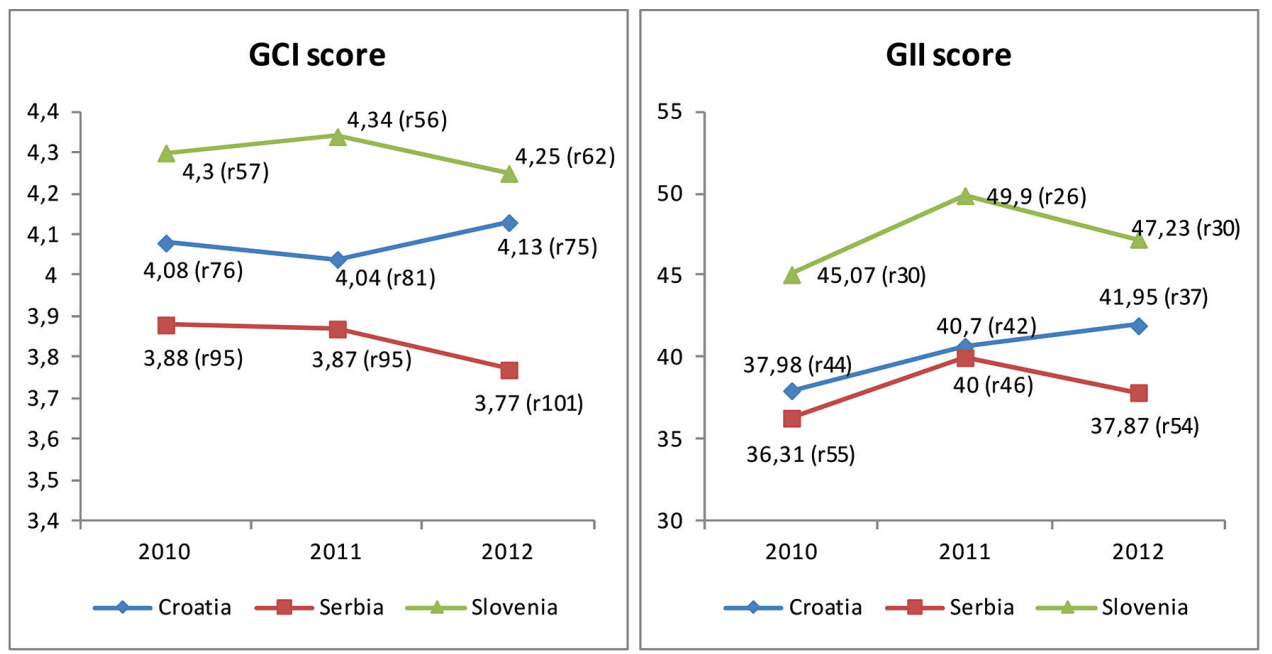

Figure 5: Scores (ranking) of countries according to Global Competitivenes Index (GCl) and Global Innovation Index (GII); Source:(WEF, 2011,2012,2013;INSEAD\&WIPO 2011,2012,2013)

As we can notice in Figure 5, Slovenia holds the highest position among the observed countries according to both $\mathrm{GCl}$ and Gll scores (GCl ranks: 57, 56 and 62 over the observed time period; Gll ranks: 30, 26, 30). Croatia is in the second place, with GCl ranks from 76 in 2010 to 75 in 2011; and Gll ranks from 44 in 2010 to even 37 in 2012 . Serbia is definitely in the worst position, ranked $101^{\text {st }}$ in 2012 regarding $\mathrm{GCl}$ and $54^{\text {th }}$ regarding GIl. Using the results of input, process and output clusters of indicators, presented earlier in the paper, we can examine what leads to these rankings. It is not surprising that Slovenia holds the best position, since it invests most in R\&D (almost 3\% of GDP) and has the best structure of investments (government share is around $13 \%$ in 2012). Besides this, it produces the greatest number of patents among the observed countries and in 2012 it had the most charges for the use of IP (receipts). Even though Serbia is definitely the best country regarding ICT goods and service exports, it lacks R\&D expenditures (both the amount and the structure) that should be transformed into valuable output - patent applications. Also, regarding the process indicators, Slovenia has the best organizing values (both infrastructure and public administration efficiency) which enable making a good output. Croatia is in the middle, by $\mathrm{GCl}$ and Gll scores closer to Slovenia than to Serbia in 2012. Even though Croatia and Serbia are actually very close regarding the observed POC indicators, Croatia still invests more in R\&D, has a better structure of investments and consequently produces a better output. What we think is most important for Serbia is not to invest more, since the economic situation is not encouraging for taking these actions, but to reorganize the investments first. By 
this we mean that the distribution of research - basic, experimental and applied has to change in favour of applied and experimental research. So Serbia should primarily focus on the input, planning group of indicators, since the process cluster is pretty satisfying. This will lead to better output results, and consequently better results of overall competitiveness and innovativeness levels.

\section{Conclusion}

Government, as an element of the Triple Helix model, is an important player that creates collaborative R\&D projects and the necessary links among other elements (university and industry), investing in development in different fields, regions and at different levels of a country. It is the key element in enhancing a knowledge-based economy that is largely based on efficient and effective TIM. Although government R\&D investments could be vulnerable to a budgetary cut in times of economic difficulties, they are always present as incentives for the development of economy and society. Inputs, processes and outputs of government activity in TIM are important to measure and analyse in order to determine correlations, achievements and weaknesses, as a relevant basis for the future activities and decisions. It is important to note that, by using the model presented in this paper, a government impact in all three relevant spheres can be tracked, monitored and analysed for quick responding actions with policies and strategy well adapted to the concrete TIM performance in practice.

One of the advantages of this model is its balanced structure enabling a systematic approach to the broad body of indicators already in use, oriented towards better understanding the specific and most relevant role of the government in creating the innovative environment for supporting the basic TIM functions. In the model, the identified government TIM performance indicators are classified into categories related to the three basic management functions - POC, also observed as the input, process and output, respectively. The model shows the relations that exist between these categories of indicators. Planning indicators refer to the investments in technological and innovative activities; organizing indicators refer to the technological and innovative infrastructure, public administration efficiency and cooperation support, while control indicators refer to the country's R\&D results, technology transfer results and entrepreneurship outcomes. Each of these categories and groups refer to the specific government TIM performance indicators, which are accessible in large internet databases such as the World Bank, OECD, UNdata, UNDP, etc. We tested the created model in the cases of Serbia, Croatia and Slovenia, and showed how the collected data can be analysed in order to track dynamics and measure changes that occur, notice the interactions between the elements of the model and use the feedback as a support in making strategic management decisions in the area of TIM at the country level. For this analysis we selected fifteen indicators and tracked changes over the period 2007-2012. Conducting this research, we have shown the applicability of the presented model in different national economies and how it is possible to use the model for relevant cross-country comparisons. By introducing official $\mathrm{GCl}$ and Gll scores of countries as a feedback in the model, we have proven the importance and relevance of the presented model.

\section{LITERATURE}

[1] Adams, R., Bessant, J., \& Phelps, R. (2006). Innovation management measurement: A review. International Journal of Management Reviews, 8(1), 21-47.

[2] Bandura, R. (2008). A survey of composite indices measuring country performance: 2008 update. Office of Development Studies, New York: United Nations Development Programme.

[3] Caerteling, J.S., Halman J.I.M., Song, M., Doree A.G. and Blj.J.D. van der (2013). How relevant is government championing behavior in technology development, Journal of product innovation management, 30(2): 349-363.

[4] Chang-Yang, L. (2011). The differential effects of public RD support on firm RD: The theory and evidence from multi-country data, Technovation, 31 (5-6): 256-269.

[5] Cherchye, L., Moesen, W., Rogge, N., Van Puyenbroeck, T., Saisana, M., Saltelli, A., \& Tarantola, S. (2008). Creating composite indicators with DEA and robustness analysis: the case of the Technology Achievement Index. Journal of the Operational Research Society, 59(2), 239-251.

[6] Cunningham, S.W., Kwakkel, J. (2011). Innovation Forecasting: A case study of the management of engineering and technology literature, Technological Forecasting \& Social Change, 78: 346-357.

[7] Eskandari, H., Sala-Diakanda, S., Furterer, S., et al. (2007). Enhancing the undergraduate industrial engineering curriculum, Defining desired characteristics and emerging topics, Education + Training, 49 (1): $45-55$. 
[8] Etzkowitz, H, Leydesdorff L. (2000). The dynamics of innovation: from National Systems and "Mode 2" to a Triple Helix of university-industry-government relations, Research Policy, 29: 109-123.

[9] Etzkowitz, H. (2002). The Triple Helix of University-Industry-Government: Implications for Policy and Evaluation, Working Paper 2002-11, Institutet för studier av utbildning och forskning, Stockholm.

[10] Etzkowitz, H. (2008). The Triple Helix: University-Industry-Government Innovation in Action, Rutledge, London.

[11] INSEAD, \& WIPO (2011). The Global Innovation Index 2011 - Accelerating Growth and Development, Available at: http://www.wipo.int/edocs/pubdocs/en/economics/gii/gii_2011.pdf

[12] INSEAD, \& WIPO (2012). The Global Innovation Index 2012 - Stronger Innovation Linkages for Global Growth, Available at:

http://www.wipo.int/edocs/pubdocs/en/economics/gii/gii_2012.pdf

[13] INSEAD, \& WIPO (2013). The Global Innovation Index 2013 - The Local Dynamics of Innovation, Available at:

http://www.wipo.int/edocs/pubdocs/en/economics/gii/gii_2013.pdf

[14] Kim, S. J. (2013). Government R\&D funding in economic downturns: Testing the varieties of capitalism conjecture, Science and Public Policy, July, 1-12.

[15] Kloot, L., Martin, J. (2000). Strategic performance management: A balanced approach to performance management issues in local government, Management Accounting Research, 11: 231-251.

[16] Levi Jaksić, M. L., Jovanović, M., \& Petković, J. (2015). Technology Entrepreneurship in the Changing Business Environment - A Triple Helix Performance Model. Amfiteatru Economic, 17 (38), pp. 422-440.

[17] Levi Jakšić, M., Marinković, S., Petković, J. (2011). From Knowledge Based to knowledge entrepreneurship economy and society - the Serbian paradox, Proceedings of the 30th International Conference on Organizational Science Development, Future organization, Portorož, Slovenia, Založba Moderna organizacija, p. 720

[18] Levi Jaksic, M., Marinkovic, S., Kojic, J. (2014). Technology and Innovation Management Education in Serbia, in Levi Jaksic, M., Barjaktarovic Rakocevic, S., Martic, M., ed. Innovative Management and Firm Performance, Palgrave, McMillan, London, pp 57-63

[19] Levi Jakšić, M., Marinković, S., Rakićević, J. (2014a). Sustainable Technology Entrepreneurship and Development - the Case of Serbia, Management - Journal for Theory and Practice Management, 70, 65-73.

[20] Leydesdorff, L. (2006.), The Knowledge-Based Economy and the Triple Helix Model, in Wilfred Dolfsma \& Luc Soete (eds.), Understanding the Dynamics of a Knowledge Economy, Edward Elgar, Cheltenham, pp. 42-76.

[21] Marinković, S., Rakićević, J., Levi Jakšić, M. Government performance in technology and innovation management - The case of Serbia, Proceedings of the XIV International symposium SymOrg 2014: New business models and sustainable competitiveness, FON, Zlatibor, 2014.

[22] Mitanoski, T., Kojić, J., Levi Jakšić, M., Marinković, S. (2013). Developing SMEs through University Support Centres: a Comparative Analysis, Management - Journal for Theory and Practice Management, No. 67, 2013, 15-24.

[23] Ministry of Science and Technological Development - MSTD (2010). Strategy on Science and Technological Development of the Republic of Serbia for the period 2010-2015. Belgrade: Government of Serbia.

[24] Park, H., W., Leydesdorff. Longitudinal trends in networks of university-industry-government relations in South Korea: The role of programmatic incentives, Research Policy, Vol. 39, No 5, June 2010, pp. 640649

[25] Ranga, M. Etzkowitz, H. Triple Helix systems: an analytical framework for innovation policy and practice in the Knowledge Society, Industry \& Higher Education, Vol 27, No 3,August, 2013, pp 237-262.

[26] Rao, K., Meng, X, Piccaluga A. The impact of government R\&D investments on patent technology transfer activities of Chinese universities: From the perspective of triple helix theory, Journal of knowledgebased innovation in China, Vol. 4, No. 1, 2012, pp 4-17

[27] Singer, S. and Peterka, S. O. (2012). Triple Helix Evaluation: How to test a new concept with old indicators? Ekonomski pregled, 63 (11): 608-626

[28] UNdata (2015). UNdata: A world of Information - Data. Retrieved April 5, 2014, from: http://data.un.org/Default.aspx

[29] UNESCO (2015). UIS Data Centre. Retrieved November 25, 2015, from: http://www.uis.unesco.org/datacentre/pages/default.aspx 
[30] World Bank (2015). World Bank Indicators. Retrieved April 25, 2015, from: http://data.worldbank.org/

[31] World Economic Forum - WEF (2011). The Global Competitiveness Report 2011-2012. Geneva: World Economic Forum. Available at http://www3.weforum.org/docs/WEF_GCR_Report_2011-12.pdf

[32] World Economic Forum - WEF (2012). The Global Competitiveness Report 2012- 2013 . Geneva: World Economic Forum. Available at

http://www3.weforum.org/docs/WEF_GlobalCompetitivenessReport_2012-13.pdf

[33] World Economic Forum - WEF (2013). The Global Competitiveness Report 2013-2014. Geneva: World Economic Forum. Available at

http://www3.weforum.org/docs/WEF_GlobalCompetitivenessReport_2013-14.pdf

Receieved: January 2016.

Accepted: February 2016.

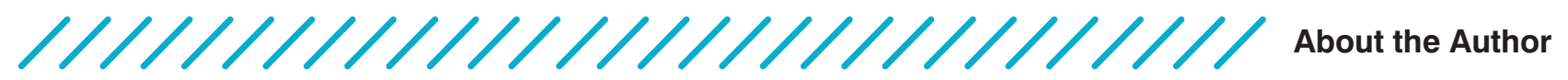

\begin{abstract}
Maja Levi Jaksić
University of Belgrade, Faculty of Organizational Sciences, Serbia levi-jaksic.maja@fon.bg.ac.rs
\end{abstract}

Maja Levi Jaksić, PhD, is a full professor at the University of Belgrade, Faculty of Organizational Sciences, and Head of Department for Technology, Innovation and

Development Management. Prof Levi Jaksic has published more than 200 works, among which more than 20 books and monographs and has been engaged in fundamental and applied research projects. She has lectured as visiting professor at universities in Greece, the United Kingdom, Japan, and France and is the programme leader of the dual diploma Academic Master programme in International Business and Management, organized in cooperation with the Middlesex University from London. She is a member of the Editorial Board of Technovation.

\section{Sanja Marinković \\ University of Belgrade, Faculty of Organizational Sciences, Serbia marinkovic.sanja@fon.bg.ac.rs}

Sanja Marinković, PhD, is an assistant professor at the Faculty of Organizational Sciences, Department for Technology, Innovation and Development Management, at the University of Belgrade. She is an author and co-author of several books and more than 60 scientific papers. She is a lecturer at dual award master programme International Business and Management, validated by the Middlesex University London. Her research and teaching interests lie in the fields of technology and innovation management, sustainable development and SMEs development.

Jovana Rakičević University of Belgrade, Faculty of Organizational Sciences, Serbia jovana.rakicevic@fon.bg.ac.rs

Jovana Rakičević, MSc, works as a teaching assistant at the University of Belgrade,

Faculty of Organizational Sciences, Department for Technology, Innovation and

Development Management. She is currently enrolled in PhD studies - Information

Systems and Management. She is an author and co-author of about 20 scientific research papers. Her research and teaching area of interest includes Technology and Innovation Management at micro and macro levels, Performance Measurement, SMEs Development, Sustainable Development and Technology Entrepreneurship.
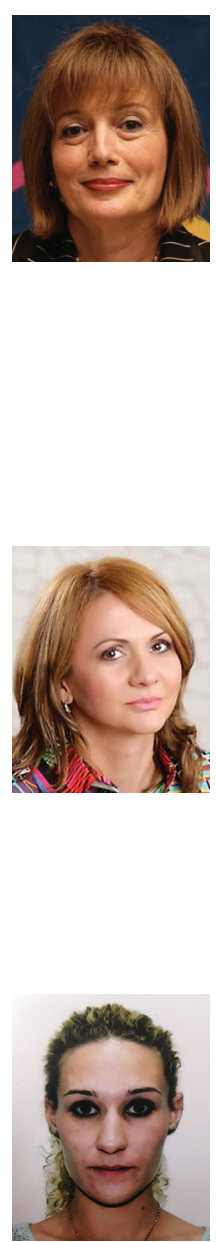